This item was submitted to Loughborough's Research Repository by the author.

Items in Figshare are protected by copyright, with all rights reserved, unless otherwise indicated.

\title{
Graphic objects and their contribution to the image of the city
}

PLEASE CITE THE PUBLISHED VERSION

http://dx.doi.org/10.1080/13574809.2015.1031211

\section{PUBLISHER}

(c) Taylor \& Francis

\section{VERSION}

AM (Accepted Manuscript)

\section{PUBLISHER STATEMENT}

This work is made available according to the conditions of the Creative Commons Attribution-NonCommercialNoDerivatives 4.0 International (CC BY-NC-ND 4.0) licence. Full details of this licence are available at: https://creativecommons.org/licenses/by-nc-nd/4.0/

\section{LICENCE}

CC BY-NC-ND 4.0

\section{REPOSITORY RECORD}

Harland, Robert G.. 2019. "Graphic Objects and Their Contribution to the Image of the City". figshare. https://hdl.handle.net/2134/18341. 
This is an Accepted Manuscript of an article published by Taylor and Francis in the Journal of Urban Design on $15^{\text {th }}$ May 2015, available online at:

http://wwww.tandfonline.com/10.1080/13574809.2015.1031211

or

http://dx.doi.org/10.1080/13574809.2015.1031211

If citing from this Accepted Version, please refer to the Published Version (the Publisher's PDF or Version of Record) for accurate page numbers.

The online article citation (as recommended by the journal) is:

Robert George Harland (2015): Graphic Objects and their Contribution to the Image of the City, Journal of Urban Design,

DOI: $10.1080 / 13574809.2015 .1031211$ 


\title{
Graphic objects and their contribution to the image of the city
}

\author{
Dr. Robert George Harland \\ Loughborough University \\ Leicestershire \\ United Kingdom \\ LE11 3TU \\ r.g.harland@lboro.ac.uk
}

\begin{abstract}
This article explores the relationship between graphic objects and urban environments by adopting a critical stance towards the notion of image in the image of the city. It challenges the emphasis on image as a multi-sensory mental construct by revealing it to have different meanings in diverse disciplinary contexts. In exposing how a miscellaneous range of objects cited in the literature lacks cohesion and sense of function, the urban graphic object is introduced and illustrated as a pervasive epistemic phenomenon. Understanding urban graphic objects expands established ideas about legibility and how urban objects have intended and unintended graphic properties. Through considering the function of graphic communication within the function of cities and urban places, the article introduces a framework for considering graphic design as urban design and graphic objects as urban objects.
\end{abstract}

\section{Keywords}

graphic image, graphic object, urban object, mental image, design

\section{Introduction}

This article focuses on how the relatively unacknowledged activity of graphic design may be understood as contributing to urban design. Starting with a brief synopsis of what graphic design is, it reveals problems associated with the jargon used to identify the phenomenon of the urban graphic object. Using situated examples, Lynch's Image of the City (1960) idea is expanded by introducing the notion of the graphic and typographic image of the city. The intention is to show how some defining properties of graphic design have a similar relationship to urban design as that of the established built environment professions architects, landscape architects, city planners and civil engineers. 
Comparable to these professions, graphic design has independent and overlapping concerns with urban design and its associated activities. This is represented in Figure 1 by adapting Jon Lang's depiction of urban design's present state to incorporate the relationship between graphic design and urban design. In essence, a key intention is to determine how graphic objects are situated within the urban fabric and thus contribute to the image of the city.

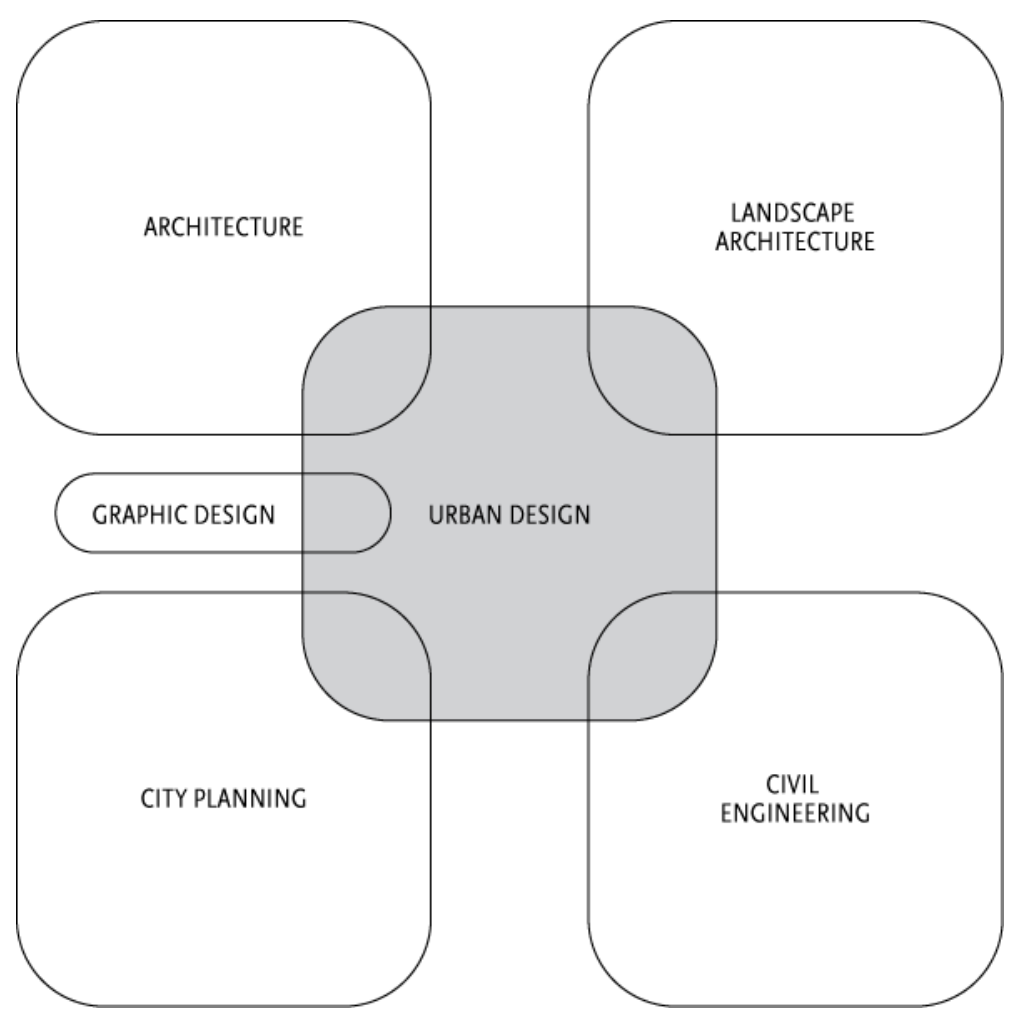

Figure 1. The proposed relationship between graphic design and the present state of the field of urban design (after Lang, 2005).

Throughout this article a preference for object rather than image is emphasised because it suggests entity, purpose and externality whereas image is more ambiguous, sometimes referring to a tangible or intangible, internal or external construct. The literature reinforces this. For example, Lynch (1960) is concerned with mental interpretations of the city when discussing the image of the city. Furthermore, Venturi et al. (1977) use image to stand for symbolic and representational elements: image is analysed and emphasised over process and form, leading to detailed scrutiny of ornament, adornment, sculpture, denotation, connotation and iconography associated with ducks and the decorated shed. 
The problem with image is that different interpretations reside in theoretical, critical and practical contexts (Manghani et al. 2006, p. 1) meaning classification is problematic. Although image offers the capacity to relate the physical and metaphysical, and may be graphic, optical, perceptual, mental and verbal, (Mitchell 1986) it carries too much ambiguity for the purpose here. For example, mental images can be "dreams", "memories", "ideas" and "fantasmata" whereas graphic images might be "pictures", "statues" and "designs" in an art historical sense (Mitchell 1986, p. 10).

Graphic design is manifest in the multitude of images and objects that communicate and represent the relations and associations between humans and their built environment. These objects contribute to what Lynch called "imageability: that quality in a physical object which gives it a high probability of evoking a strong image in any given observer" (1960, pp. 9-10). The ubiquitous red octagonal stop sign possesses this quality, as does graffiti art in São Paulo, or the distinctive black and white cobbles that pattern much of Lisbon's floorscape. These diverse examples, seen in Figure 2, appeal "sharply and intensely to the senses" in the semblance of graphic urbanism. They stand out and are the products of a particular kind of thinking referred to here as graphic designerly ways of knowing (after Cross 2006) that leads to "graphic decisions" (Arnold 2013, p. 422).
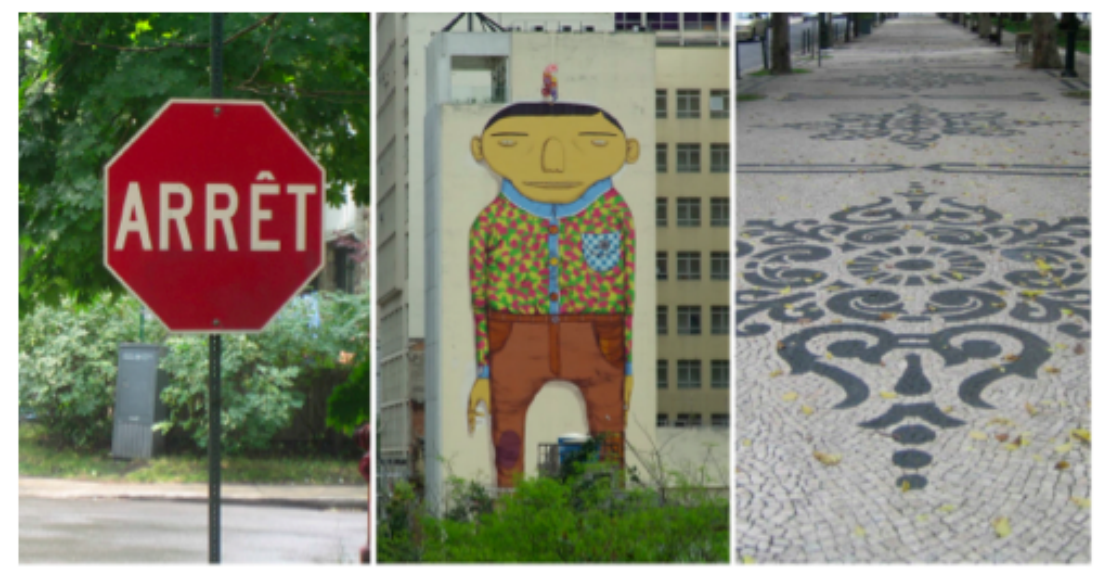

Figure 2. This stop sign in Montreal, graffiti art in São Paulo and floorscape in Lisbon possess "imageability." Each display distinctive properties likely to stimulate the visual sense more than usual, contributing to the formation of a strong mental image.

\section{Defining graphic design as the source of graphic objects}

The term graphic design is used broadly in this article. Its modern day usage builds on a history rooted in the early development of writing systems 
approximately 5000 years ago in Mesopotamia's early urban settlements (Friedman 1998; Robinson 2007). A detailed history of the subject continues to be documented - Jubert ([2005] 2006), and Meggs and Purvis (2006) providing two of the more substantial tomes respectively from European and American perspectives.

Recent graphic design history increasingly draws from the urban environment and continually registers and adopts exemplars from conscious and unconscious sources. For instance, graphic design incorporates the Mobil Oil trademark designed in 1964 by corporate identity specialist Chermayeff and Geismar Associates, as well as the McDonald's golden arches symbol by sign-maker George Dexter, which originated in 1953 as an architectural flourish. Both are fixtures in the urban landscape having emerged in the 1960s as formal designs, the latter becoming "one of the most recognisable and iconic designs in the world" (Terragani 2012). Graphic design also historicizes mundane objects by unknowing graphic designers, such as the longitudinal stripes of the ubiquitous pedestrian crossing (Terragani 2012). Effective and affective graphic objects fall within the purview of graphic design, regardless of their origin.

Professional recognition of graphic design is less than a century old. Recognising need for "a suitable blending of common sense with artistic talent," (Dwiggins [1922] 1999, p. 18), the inception of the term by W. A. Dwiggins in 1922 signalled an attempt to raise awareness and standards of graphic artisanship in artists working across a number of integrated practices focused on printed matter. In the post-war years of America and the United Kingdom graphic design named what Livingston and Livingston describe as the integrated use of typography, illustration, photography, and printing for the purpose of persuasion, information or instruction (1992, p. 90). This is now a limited description because it has since evolved to stand for an expanded range of specialist activities producing static and dynamic analogue and digital communication in two, three and four dimensions. Information design, advertising, corporate identity, packaging, publishing and branding are some of the typical applications, but its reach is extensive and increasingly identified in multiple contexts, as explained in the following exposé. 
Graphic design is everywhere, touching everything we do, everything we see, everything we buy: we see it on billboards and in Bibles, on taxi receipts and on Websites, on birth certificates and on gift certificates, on the folded circulars tucked inside jars of aspirin and on the thick pages of children's chubby board books. Graphic design is the boldly directional arrows on street signs and the blurred, frenetic typography on the title sequence to "E.R." It is the bright green logo for the New York Jets and the monochromatic front page of The Wall Street Journal. It is hang-tags in clothing stores, playbills in theatres, timetables in train stations, postage stamps and cereal box packaging, fascist propaganda posters, and junk mail. It is complex combinations of words and pictures, numbers and charts, photographs and illustrations that, in order to succeed, demand the clear thinking of a particularly thoughtful individual who can orchestrate these elements so they all add up to something distinctive, or useful, or playful, or surprising, or subversive, or in some way truly memorable. Graphic design is a popular art, an applied art and an ancient art. Simply put, it is the art of visualizing ideas. (Helfland 2001, p. 137)

This expansive depiction of graphic design hints at independent and overlapping concerns with urban design. With increasing recognition for an array of artefacts that embellish and adorn the urban environment, it is timely to explore how the phrase might be put to better use in urban discourse.

Products of graphic design pepper the built environment: billboards, street signs, logos and timetables are only some. Graphic intervention through the coded combination and application of vivid visual devices as meaningful mediated communication shapes behaviour in cities and is increasingly relied on to do so. However, there is little consensus about how this phenomenon is discussed by those interested in associating graphic communication and the built environment. There has not yet emerged a unified discourse that defines graphic objects as urban objects due to the plethora of things, names and phrases that designate it as a knowing and unknowing practice. For example, the practicing designer's understanding of sign is far removed from the semiotician's musings about the same word. The following list of jargon from urban commentators exacerbates the confusion: 
- Visual communication displays (Clause and Claus 1971, p. 1)

- Maps, street numbers, route signs, bus placards, way-finding devices (Lynch 1960, p. 4)

- Architectural communication, commercial vernacular, signs (Venturi et al. 1977, p. xvi)

- Outdoor publicity, lettering (Cullen 1971)

- Commercial vernacular, billboard advertising, fly posters, large scale graphic images (Crosby 1973, pp. 220-221)

- Traffic and direction signs (Carmona et al. 2010, p. 196)

- Inscription (Mitchell 2005, pp. 3-19)

- Public signing and lighting, outdoor information media, environmental information systems (Carr 1973, p. 3)

- Manhole, nineteenth century graphics (Rowe and Koetter 1978, p. 33)

- Official, unofficial and illegitimate public messages (Zeisel 2006, pp. 177-178)

- Urban visual culture, aesthetic surfaces, functionalist façades, electric stimulations (Ward 2001, p. 195)

Publications on urban design are equally fragmented in their interpretation. For example, The Design of Urban Space (Anon 1980) refers to an exhaustive assortment of signs, advertising, information, traffic signs, pedestrian signs, hoardings, poster boards, name signs, placards for commercial advertising, public information, notice boards, bus information, town maps, street finders, secret signs, gantries, street name plates/boundary signs, bus/train signs, advertising posters, commercial name signs, awnings/sunblinds, lifesaving equipment, flagpoles, clocks, pedestrian crossings and illuminated traffic bollards. Furthermore, the UK based Design Council and Royal Town Planning Institute publication Streets Ahead (Anon 1979) foregrounds the painted mural, poster units, information boards, display cabinets, decorative paving, coloured surfaces of a bus lane, systematic signage, symbolic or written representations, and lettering.

This fragmented disciplinary discourse ill-prepares urban designers for the communication challenges facing the twenty-first century metropolis when cities are said to be needing close attention after rapid growth in the twentieth century (Leite 2013, p. 198). Consequently there is need for a new perspective on the physical, social, visual, effective and affective graphic object as urban object in the 
guise of graphic design as urban design. By treating graphic design as a typology within urban design, the intention here is to situate graphic objects as distinct products that may be understood alongside the products of architecture, landscape architecture, city planning and civil engineering and their relationship to the nature of urban design. Therefore throughout this article the terms graphic design and graphic objects respectively name the process and products of thinking graphically. To appreciate this potential from an urban perspective, it is necessary to further explore, substantiate and understand what graphic means.

\section{What is graphic?}

In simple dictionary terms graphic encompasses writing, drawing, and explicit vivid detail relating to visual art. These are the basic qualities in focus here. However, for the purpose of applying this way of knowing to the urban environment, a more complex interpretation is borrowed from what geographers call graphicacy. They explain graphicacy as the "skills of reading and constructing graphic modes of communication, such as maps, diagrams and pictures" (Clifford et al. 2009, p. 343) concerned with communicating spatial information (Boardman 1983, preface). Graphicacy is said to stand for "fluency in the construction and interpretation of graphic modes of communication (graphs, diagrams, illustrations, photographs, sculpture, icons, and maps)" (Monmonier 1993). This implies that as well as writing and drawing, graphic messages are designed through the conceiving, planning and making in two, three and four dimensions. Thus, as urban design graphic design may be understood to define the conceiving, planning and making for meaning urban graphic communications as static or moving objects at different scale across space and time. This is evident in three rudimentary examples shown in Figure 3. As urban graphic objects, the structural and infrastructural components are designed entirely to serve graphic communication needs. 

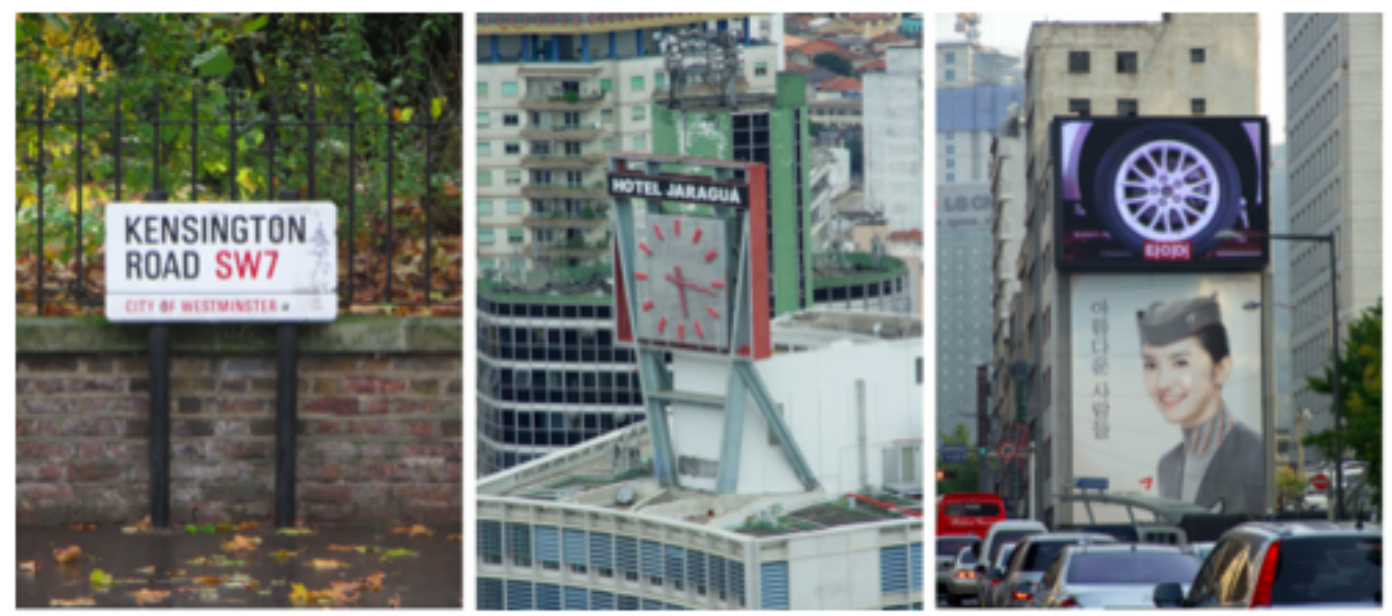

Figure 3. Graphic objects may be two, three or four dimensional, comprising structural and infrastructural components in the service of graphic communication. The various defining properties are arranged in a meaningful configuration to convey individualistic and systematic messages on a local and global scale. These examples demonstrate that graphic objects consist of more than mere applied images as patterns, pictures and writing.

This interpretation of graphic is more expansive than the meager understanding of "graphic in drawings" (Lang 1994, p. 170), implying graffiti in the illegitimate or legitimate public art sense. It is also differentiated from the products of "graphic communication" that visualize urban design ideas in what Carmona et al. (2010, pp. 331-354) call "the communication process" - this being more akin to the way comprehensive plans are the product of city planning.

By referring to the group of objects listed above as a category under the rubric of graphic design, it is possible to further consider how the working of cities is increasingly reliant on graphic objects, and think more critically about how these are deployed as part of a design process. This has relevance because understanding the scope and complexity of mediated communication in urban environments has been restricted by the incongruent nature of planning and design for different modes of communication (Lang 1994, p. 171). Thus, in Urban design: a typology of procedures and products, Lang (2005) concentrates more on the procedures and products of urban design associated with new towns, urban precincts, and elements of infrastructure, and less on the phenomena in question here, which is said to merely "add lustre." Lang does not go any deeper than refer to a "miscellaneous" category of objects comprising works of art (for example sculptures and murals), monuments, fountains, clock towers and street furniture, intermittently mentioned in case studies. At times, these are called "urban objects," meaning banners, signs, large screens, and "smart skins" on buildings (2005, p. 143). Examples feature in discussion about the refurbished 
building complex at Ghirardelli Square in San Francisco, where large handcarved wooden signs, directory boards, banners, and neon lighting are noted (2005, p. 142). This is insufficient. With the exception of fountains and certain items of street furniture (such as a bench), all of these function primarily as modes of graphic communication contributing to the graphic image of the city (after Lynch 1960). They contribute vividly to forming mental images, and make a place, city or country legible.

Times Square, New York provides an example of this at different geographic levels. An environmental image of Times Square is formed by the animated digital displays that encase the intersection of Broadway and Seventh Avenue; a wider experience of New York is more distinctly represented by the letter and number colour coded circle system of its subway; the plethora of traffic signals (some cased in yellow armature), street signs and their typographic styling, impress on us a visual representation of America; and the pedestrian (or zebra) crossing is a pervasive urban graphic object, and arguably one of the most recognizable symbols of the streetscape. See Figure 4.

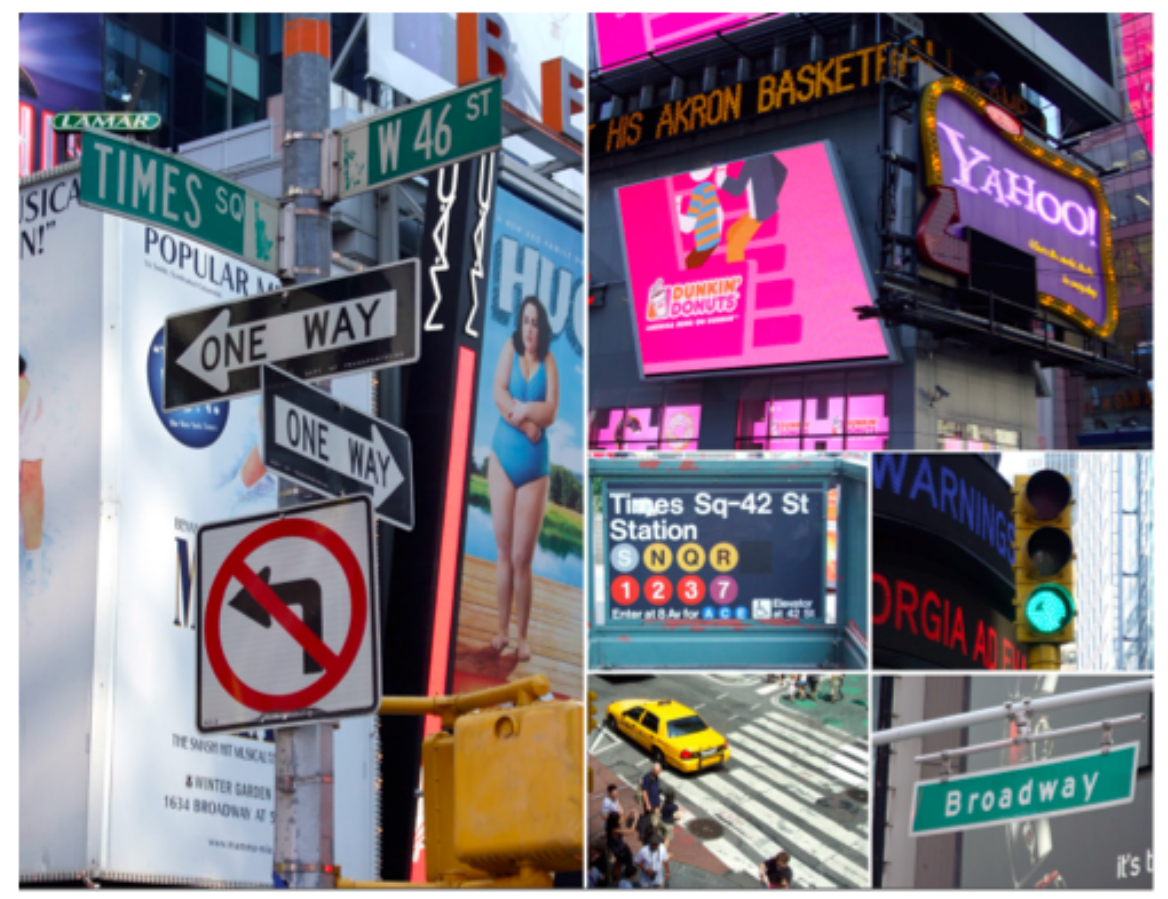

Figure 4. Times Square in New York displays an array of public, private, official and unofficial graphic objects that contribute to our mental image of that place, as well as distinct aspects we may hold of the universal urban image such as a pedestrian crossing.

Each of these products can be analysed in terms of an ensemble between form and context, and degree of fit (Alexander 1964). In the case of the graphic in 
graphic design, this determines the distinctiveness of form, tempered by the "appropriateness" that Cross (2006, p. 2) argues is associated with value in design. Graphic objects reside on a continuum between convergent and divergent form-context relationships. For example, Figure 5 shows two signs designed with environmental fit and misfit in mind. One blends in and the other stands out: both possess elements that contrast, but one relies only on the whiteness of lettering to be read whereas the other demands attention through vivid colour and large typography with distinctive individual letter shapes such as the miniscule g.
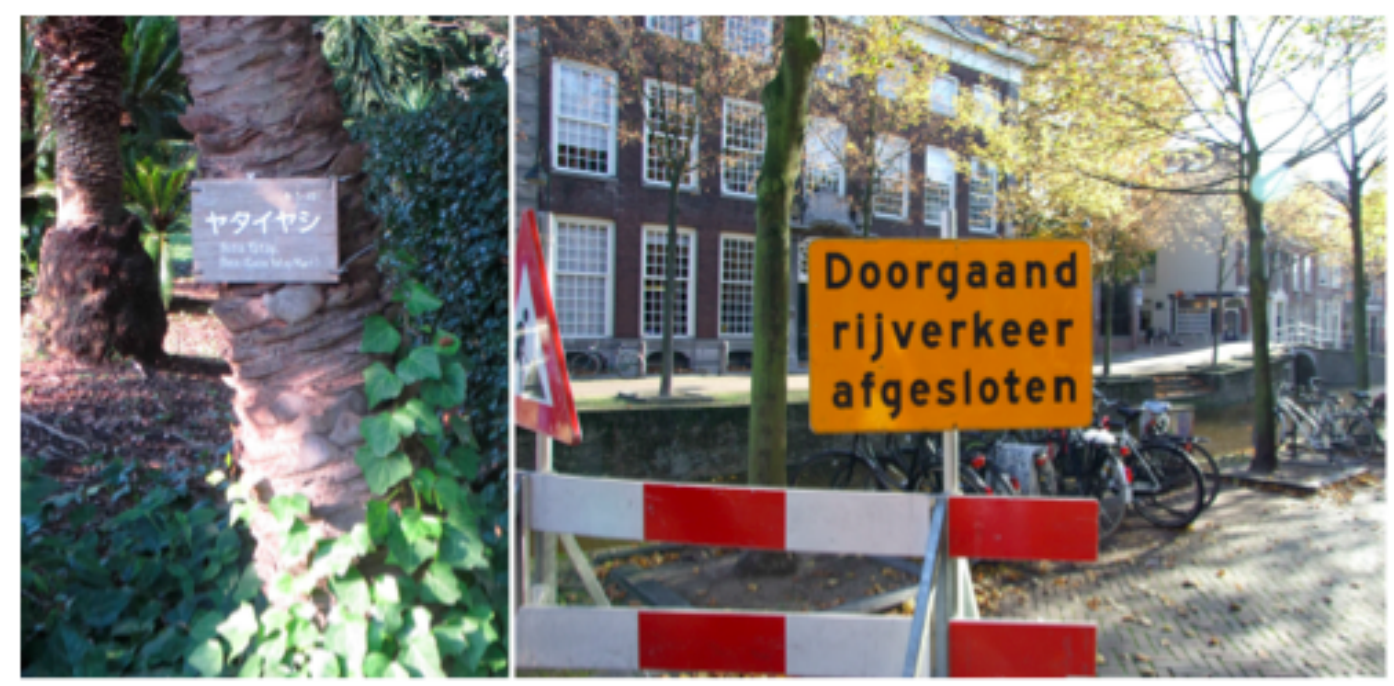

Figure 5. Two graphic objects designed to demonstrate through their materiality, shape and colour, environmental fit and misfit. Although both form and context relations mean that each ensemble is a good fit in terms of message conveyance.

There is a need to establish graphic objects as urban objects by extending Lynch's ideas about the image of the city with a focus on the way graphic objects contribute to the graphic image of the city. The following expands this by concentrating on one of the key metaphors used by Lynch to explain legibility, then focusing on a detail within this and finally by considering graphic objects and urban elements as well as a graphic objects in urban elements.

\section{Substantiating the graphic image of the city}

The foundation for a relationship between graphic objects and urban environments was established by Lynch (1960) but this is generally unexplored and unacknowledged. For example, in The Legibility of the World: A Project of Graphic Design, Moles (1989) identifies "real space" and the "printed page" as graphic design space, using the same metaphor as Lynch but without recognition. 
Furthermore, and inspired by Lynch, Gouveia et al. argue that "the visual, aesthetic and cultural identity of the city is made up of, amongst other things, its graphic elements" yet they do not attempt to define what these elements are beyond the mention of "urban flows (wayfinding)" and "landmarks" (2009, pp. 344-345). Instead, they quickly revert to what they call the "typographic landscape."

In The Image of the City, Lynch (1960) analogised the intelligibility of the American cityscape by using graphic communication as a metaphor. He implores the reader to consider: "Just as this printed page, if it is legible, can be visually grasped as a related pattern of recognizable symbols, so a legible city would be one whose districts or landmarks or pathways are easily identifiable and are easily grouped into an overall pattern" (1960, p. 3). This contrasts the relative simplicity of page design with the complexity of city design, the essence of the metaphor being the relationship of the parts to the whole. Lynch sought to use the printed page to understand legibility, but without explaining the parameters of design decision making that contribute to the legibility of a page. Use of analogy in this way for understanding urban complexity is a familiar approach of urban thinkers (Strauss 1961, p. 12) and through this Lynch unknowingly establishes the direct link between graphic design and urban design thinking.

The page design Lynch refers to utilizes typographic and non-typographic elements including a multitude of photographs, diagrams and drawings to enhance the text and assist the reader. Directional signs, signs indicating proximity to shopping nodes and street names, and visual examples appear in photographs of Journal Square in New Jersey City, The Civic Centre and Broadway in Los Angeles, and Boston's subway, Washington and Summer Streets, and Scollay Square. Collectively these are predominantly typographic but some photographs feature a clock, flags, car registration plate and a picture of a motorcar, as Lynch links signs and other details such as 'arrows' to legibility.

Common themes exist between the idea of graphic objects and Lynch's writing on the city image. "Clarity of structure and vividness of identity" and a sensual aspiration towards a 'highly developed art of urban design' are central to his ideas about legibility. Vividness and art are pertinent here. Moreover, there is an infinite diversity of texture and detail in "thematic continuities" that define 
districts, specifically referring to "lettering", "house numbers", "street names", "traffic signs", "directional signs", "glaring signs" and signs as "way-finding devices'. Signs are also important for continuity and point references in physical objects such as a "building, sign, store, or mountain" that represent landmarks. Distinctive signs are seen as reinforcing "clues" for enhancing the identity of a district. Within this the urban designer's interpretation and importance attached to the word "sign" reinforces the confusion in interdisciplinary discourse.

These terms and phrases by Lynch and others represent some of the visual "messages" experienced in urban environments but there are other graphic objects that contribute to the working order of a city and its imageability beyond those noted so far. For example, Figure 6 shows the lines of a football pitch, road maintenance workers, liveried vehicles, warning tape on scaffold, a red carpet outside a church, helipad, topiary and illuminations.
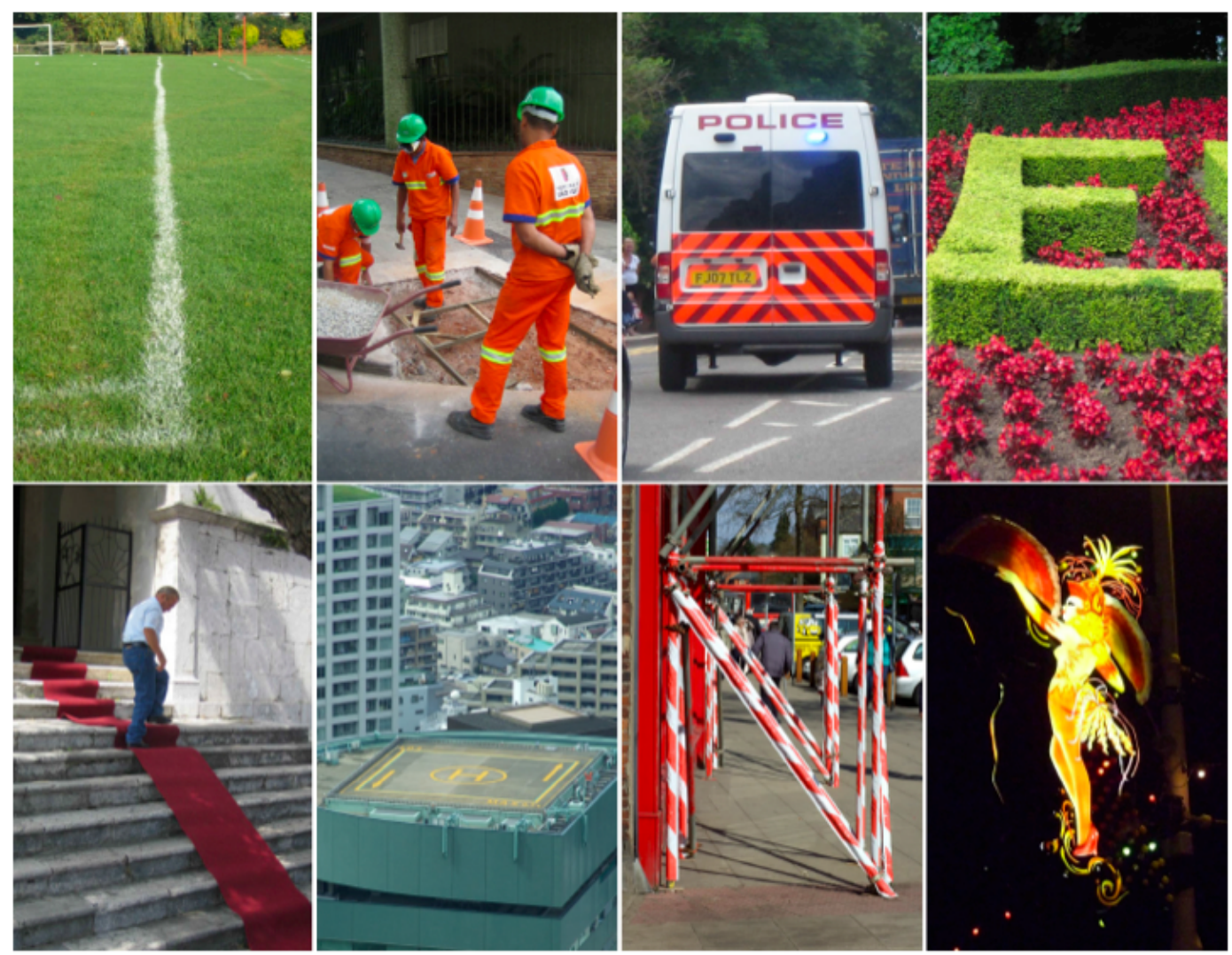

Figure 6. Graphic objects also comprise an overlooked myriad of things that affect behaviour and depict more than words say.

Objects such as these communicate but the ambiguous nature of the term communication (Buchanan 1989, p. 91; Williams 1983) and its association for 
urban designers with transport infrastructure impedes the opportunity to refer to these as communication objects. Doing so would need to extend this discussion and include non-visual examples such as the sound of a church bell or the smell of a bakery, and how these contribute to the mental image. These are not a concern here.

A common word used to describe graphic objects is sign, but this is unsatisfactory. Sign is most often associated with the kind of everyday object (analogue or digital) recognized by Lynch. Then again, a sign can be "any phenomenon that has a meaning" (Mollerup 2005, p. 11). "Signs are everywhere; there is nothing that is not potentially or actually a sign' (Mitchell, 1986, p. 62). This is a critical distinction when discussing urban graphic objects because it allows the possibility for a multitude of objects to be identified as graphic objects.

In Wayshowing, Mollerup (2005) employs the distinction between "sign" and "SIGN" to respectively differentiate between everyday use and how semioticians use the word. Figure 7 depicts this relationship. SIGN is the preferred interpretation in the study of semiological schema in the relationship between signifier, signified and sign (Barthes [1957] 2009, pp. 131-187). For example, a structure such as the Empire State Building in New York may be considered a SIGN - that you are approaching Manhattan - but it is not a sign. The problem with the word sign is that it does not necessarily evoke distinction or vividness, although Mollerup's typographic differentiation does help us to migrate between primary (sign) and secondary (SIGN) appearances of graphic objects in the urban environment. SIGN in the semiotic sense helps the understanding of meaning in communication regardless of the form. SIGNS categorized in this way enable us to consider New York's Empire State Building as a semiotic symbol, even though it is the product of architecture. When the building's silhouette is seen as part of the Manhattan skyline, and shape alone is pre-eminent, this performs the role of a graphic object contributing to what Lynch suggests as standing for "vitality, power, decadence, mystery, congestion, greatness, or what you will" through the image of the skyline (1960, pp. 8-9). The Empire State Building as a SIGN is shown in Figure $8 \mathrm{a}$ whereas its sign is seen in Figure $8 \mathrm{~b}$. 


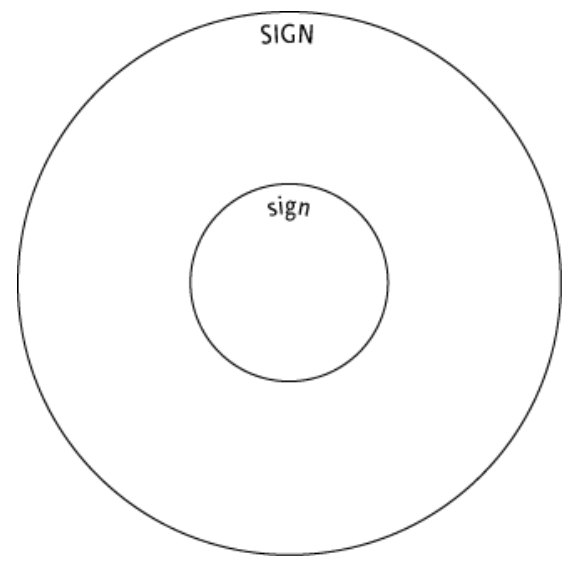

Figure 7. The everyday "sign" and semiotic SIGN render this relatively useful word confusing in the context of the graphic object. Source: Mollerup $(2005,10)$, redrawn by the Author.

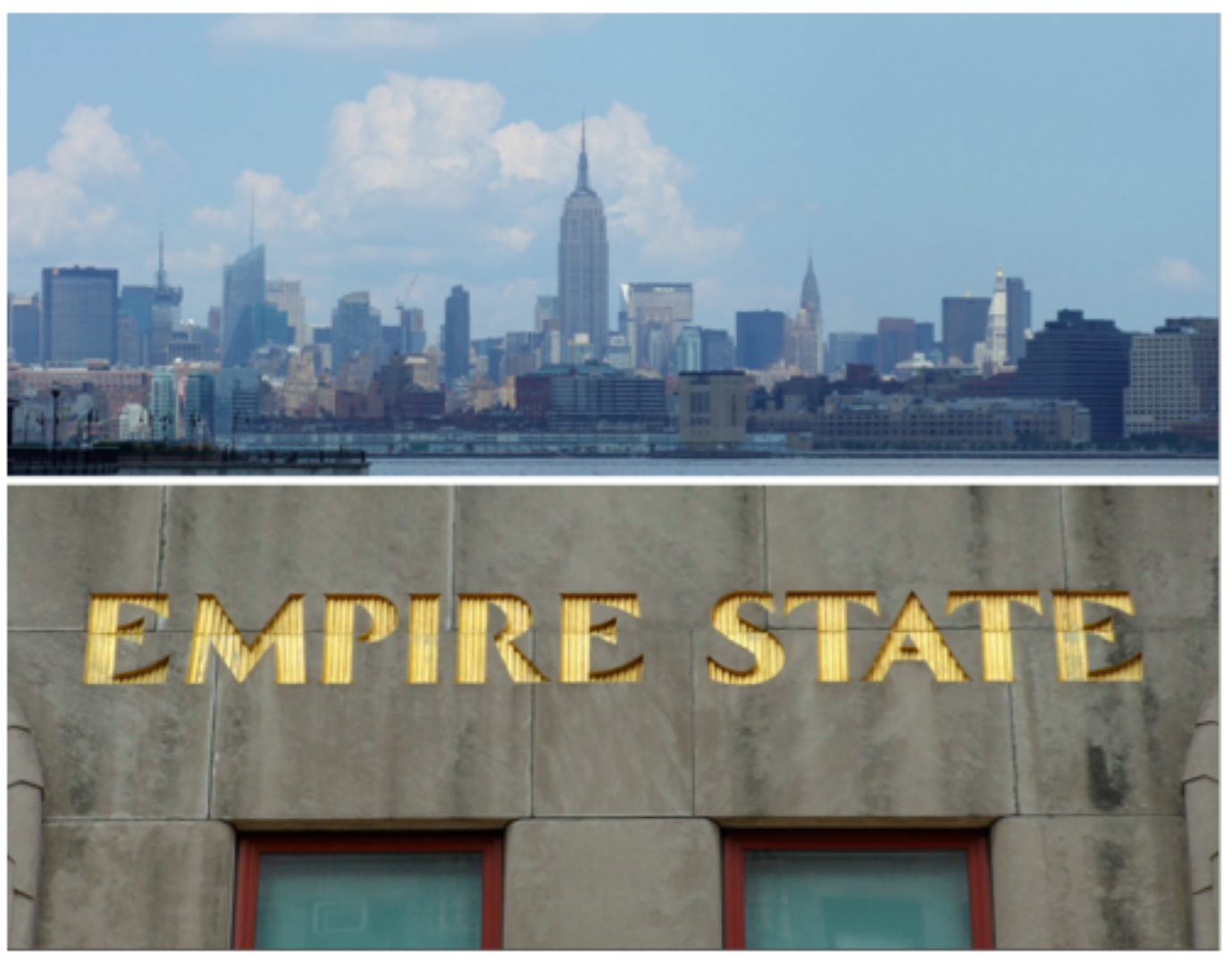

Figure 8. (a, top) Empire State Building SIGN (2010, looking North East from The Waterfront district, Jersey City) and (b, top) Empire State Building sign, (2014, building façade lettering facing $5^{\text {th }}$ Avenue), as respective secondary and primary graphic objects.

If valued for these visual qualities alone, the products of architecture, landscape architecture, city planning and civil engineering, within the context of urban design, have the potential to be read as meaningful secondary graphic objects, contributing to the graphic image of the city. At a basic level, a picture of the Empire State Building denotes architecture. At a more complex level, it carries 
connotations of also being a graphic object conveying the messages Lynch believes associated with the Manhattan skyline, or any other that possess defining silhouettes. Everyday graphic images of the city are distinct and enhance our spatial understanding in practical and emotional ways, reinforcing Lynch's ideas about identity, structure and meaning. The decorative gold engraved lettering of the Empire State Building sign is part of the building's fabric, yet in terms of letter shape and colour it stands out as distinct, as does the building itself. In this sense decoration is important and valued by Alexander et al. (1977) when interpreting ornamentation as pattern. Decorations and ornaments 'have a function, which is as clear, and definite as any other function in a building' (1977, pp. 1146-1152), referring primarily to "simple themes" found at "corners, places, main entrances, ... the garden gate, a fence, ... the edges and boundaries" needing "emphasis or extra binding energy." Typical examples are found in some form or other on residential housing, such as decorative brickwork or patterns carved into the fascia boards of a roof.

Alexander et al. interpret the essence of this in two simple but effective drawings. See Figure 9. One shows two adjacent rectangles, the other incorporates an incision in both rectangles to depict the conjoined shape of a heart. In this, the heart demonstrates the power of visual mediation for unifying otherwise independent things. This visual metaphor can be used to portray the power of graphic communication as a relational device in other contexts. The heart shape is irrelevant but as implied it represents an important mediating device as an intervening act of unification between two entities. Urban graphic objects do this.
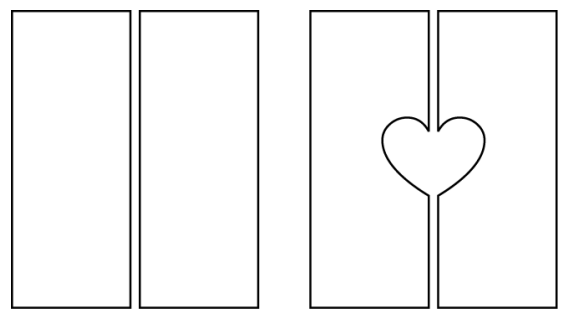

Figure 9. Christopher Alexander's depiction of ornamentation uniting a split world provides a useful depiction that may also extend to include further functions of graphic design. Source: Alexander et al. 1977: 1148, redrawn by the Author.

The meaning behind this abstract representation shows its potential as a simple model for applying the principle to scale, from the largest of forms to the tiniest of particles. In the left-hand diagram two distinct entities function individually 
but not together as a larger whole. In the right-hand diagram the two entities are individual but they are also united as a larger whole (1977, p. 1148). This principle of mediation depicting ornament as a pattern language is highly appropriate in a discussion about graphic objects, yet is limited in scope in the sense that most of the examples featured in this article would be inappropriately defined as ornament, though may often possess ornamental qualities. This idea can be extended through exploring how the functions of graphic design have been explained.

Many adjectives have been used to describe the point of graphic design: identification, information, presentation \& promotion, referential, emotive, connotative, poetic/aesthetic, meta-linguistic, phatic, persuasion, education, administration, decorative, magic, representation, orientation and systematic (van der Waarde 2009, p. 23). Moles (1989, p. 122) suggests "The work of the graphic designer, spread over the city or the social space-time, classically fulfills a series of functions: ... information, ... propaganda, ... social consciousness, ... consonance of humans with their goals". This is brief compared to discussion about the function of graphic design as communication. Moles defines the information function as "who does what, where, why, at what price" whereas Barnard (2005) is more elaborate in acknowledging the informative function is to “impart (by definition new) knowledge, or intelligence." For example "pub signs, shop-fronts, coats of arms, company logos and packaging" provide elementary information. Similarly, Barnard goes on to say "signage, in our towns and cities, on our highways and motorways, along with maps, diagrams, portraits, landscapes and much illustrative work are also providing information." Signage in this sense is something that not only directs or names; advertising messages are also signs of a kind, conceived and planned with coercion in mind (2005, pp. 14-15). Barnard focuses on six functions: information, persuasion, decoration, magic, metalinguistic and phatic (2005, pp. 14-18) together acting as a functional compound. The first of these, information, is noted above and the other five are now briefly paraphrased.

Persuasion performs a "rhetorical function" and seeks to affect behaviour typically through "advertising", "political propaganda" or "electoral publicity." Although these inform, the intention is attention seeking as opposed to people seeking out of information. Pleasure seeking is the intention of decoration as 
aesthetics are directed towards "entertainment" or "ornamentation." The least palpable function is magic whereby graphic design possesses qualities described by Barnard as "sacred" and transformative. By this is meant the representation of something absent with strong emotional connotations. The last two metalinguistic and phatic - are grouped together. The first is "a communication that comments on, explains, clarifies or qualifies another piece of communication," the example given being the cartographic key on a map as coded information. Phatic devices "initiate, continue or conclude" communication and may link or direct the reader as an arrow or broken line does.

None of these functions are independent from each other, but some functions are more apparent than others. For example, a stop sign is informative more than persuasive or decorative, directly linking a driver's actions to the environment in the way Alexander et al. (1977) describe how graphic devices link distinct entities. A commemorative cross in a graveyard might suggest access to the realm of the sacred in some transformative magic-like way. Furthermore, coloured circles such as those on the New York subway provide a metalinguistic key to using the network, whilst an arrow pointing the way performs a phatic role.

This overview of graphic design's functions provides a framework for analysing the role of graphic objects in the urban object. If transposed onto what Lang identifies as the "functions of cities and urban places" - communications, economic, cognitive and display (1994, pp. 168-180) - a structure for understanding the complexity of how a category of graphic objects influences behaviour in cities becomes plausible.

To further analyze the graphic image of the city a specific property of graphic design - typography - is now introduced to enrich the argument and present a scalar contrast. Using examples from two European cities, the typographic image of the city reveals how the graphic image of the city is supported by sub-images.

\section{The typographic image of the city}

What Lynch alludes to as page design is the modern-day mechanised example of what Meggs and Purvis describe as early Sumerian pictographic writing structured on a horizontal and vertical grid (2006, p. 7). Hand lettering in an orderly fashion with a reed stylus on clay is the precursor of printing as it has 
developed over the last 500 years. During this period typography emerged in the late nineteenth century having been directly associated with craft and printing since the seventeenth century (McLean 2000, pp. 7-35). Yet definitions of typography vary. For example Lupton provides a straightforward definition as “... the design of letterforms and their organisation in space" $(1996,29)$. Whereas Baines and Haslam determine it as "the mechanical notation and arrangement of language" incorporating both physical and digital means in a graphic system of symbolic codes representing ideas (2005, 7-8). Both suggest a difference between individual letters and their organisation.

Moreover, in the context of a discussion about typographic landscapes, Gouveia et al. interpret typography in a broader sense to mean "alphabetic and paraalphabetic characters obtained from processes that would be better described as lettering (painting, engraving, casting, etc.) and not only from automatic or mechanic processes that characterize typography in a more restricted sense" (2009, p. 345). Within this survey of environmental typography eight major groups are proposed:

1 Architectonic typography; permanent inscriptions, such as a building name or number, which are usually designed and built at the same time as the building.

2 Honorary typography; inscriptions designed to honour historical characters or events, such as those fond on most public monuments.

3 Memorial typography; funerary inscriptions found in restricted urban spaces, such as gravestones found in churches and cemeteries.

4 Registered typography; trade inscriptions, by public or private companies, such as telephone and sewage services providers, usually in gratings and manholes.

5 Artistic typography; artistic lettering designed on commission, such as paintings and sculptures using letters and numbers.

6 Normative typography; inscriptions that are part of regulatory and information systems for city traffic, such as road and directional signs. 
7 Commercial typography; lettering found on temporary signs, such as those on shop fascias, attached to a building after its construction and, in most cases, replaced by other signs from time to time.

8 Accidental typography; unofficial, unauthorized inscriptions, such as graffiti tags, usually not planned, and inscribed without permission of architects, construction companies, developers and owners.

Notwithstanding the inaccuracy some of the classification headings - graffiti is an intentional rather than accidental act - this begins to suggest the scope for determining the typographic image of the city. The following two examples further illustrate how the typographic image is part of the wider environmental graphic image. Both originated at the start of the twentieth century in France and Britain because of significant city infrastructure projects, and are still with us today.

First, the art nouveau lettering on metro station entrances in Paris provides a distinctive contribution to the graphic image of that city. This manifests in the stylised lettering for METROPOLITAIN on the Hector Guimard designed structures built between 1898-1901 (Knobel 1985, p. 56). See Figure 10. The lettering style appears in distinctive dark green on a yellow background situated above the descending steps. Within the 'exuberant floral decoration' of surrounding cast-iron work, this was used for three different entrance designs said to have strong emotional appeal that act as a landmark element in Lynch's city image.

\section{METROPOLITFiN}

Figure 10. Art Nouveau lettering at the entrance of some Paris Metro stations.

Second is Edward Johnston's 1916 humanist sans serif design for the Underground typeface of the Electric Railways Company of London (now London Underground). The typeface's defining properties derive from simple geometric form, consistent stroke weight and quirky detail derived from calligraphy. These comprise of a diamond shaped dot over the miniscule letters $i$ and $j$ as well as a 
hook at the bottom of the 1 to avoid it being mistaken as a capital I. See Figure 11. For some time now it has been the standard for all London Transport graphic communication and used recently for wayfinding at the 2012 Olympic games (Lucas 2013, pp. 26-30), this distinct yet subtle detailing connecting an aspect of the event identity to London's environmental image.

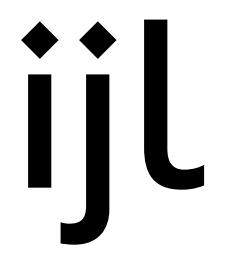

Figure 11. The idiosyncratic detail in Edward Johnston's Underground typeface distinguishes it from other sans serif typefaces such as Futura or Gill Sans, and provides an understated detail in the typographic image of the city of London.

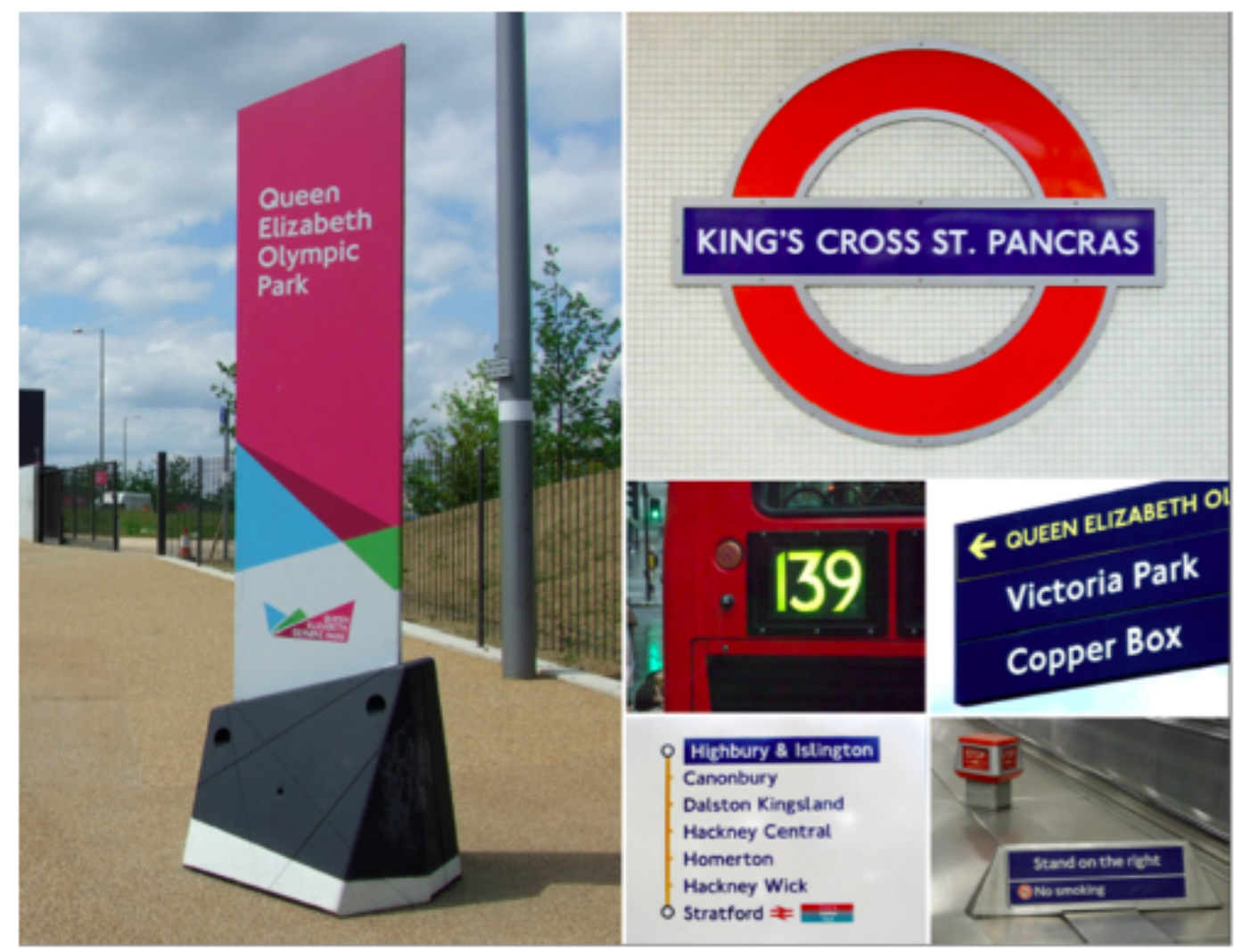

Figure 12. Aspects of London Transport's graphic design components underpinned by the consistent application of Edward Johnston's typeface design. This was most recently used for the London 2012 Olympic Games wayfinding scheme. 
The longevity and expansive nature of the latter is worth elaboration because a century has passed since Johnston received the commission in 1913 to create a typeface with clarity and distinction. It was very soon implemented across the Underground Group's communications and the commission preceded a period of architectural and design unification between 1916-29, first appearing publicly on posters for tram fares in 1917, and soon after on signs (Ovenden 2013, pp. 112147). It was integrated into the London Underground diagram (commonly known as the London Underground map) in 1933 soon after Henry Beck conceived the diagram, and has been an integral part since. Some refer to it as "London's letterform" acknowledging its contribution to London's identity.

That said, in urban design Johnston's lettering is generally unacknowledged yet its relationship to contemporary urban design is obvious as an integral part of the Jubilee Line extension underground rail link in London, a scheme referred to as "plug-in urban design" by Lang (2005, pp. 334-338). The typeface is unacknowledged by Lang, yet is implicitly part of London Underground's visually unifying signage and extended set of graphic elements that includes the roundel, colour scheme, pictograms and complete wayfinding system for the London traveller. See Figure 12.

Urban planners, designers and architects think in terms of "the material city and its objects at their disposal to manipulate and control” (Carter et al. 2011: p. 3). One of the key objectives of this article is to offer built environment professionals an improved understanding of graphic objects in order to better manipulate and control them. Until now these have been discussed to determine what they are and how they contribute to the image of the city. How graphic objects support the notion of urban design elements will now be introduced by further exploring the relationship between graphic objects and urban elements through place and product.

Graphic objects and urban elements: Times Square, New York Shane (2011) identifies the enclave, armature and heterotopia as three key elements employed by urban design actors. Some of the graphic objects discussed so far reinforce these categories. For example: the digital advertising displays that adorn the buildings in Times Square determine the perimeter of that place's attentive audience in a bounded space; the New York subway information system 
acts as a "linear spatial organising device" for each of its transport armatures, cutting through Times Square as an enclave; and the conflicting urban activities of Times Square as an heterotopia is no better represented than with the vast array of graphic objects that determine it as a place of urban experimentation and change. Then again, there is more to the presence of graphic objects and the role they play in making Times Square function.

Located at the northeast-southwest acute intersection of Broadway and Seventh Avenue, and connected to the east-west artery of $42^{\text {nd }}$ Street, Times Square is at the heart of Manhattan's midtown Theatre District. Some tourist guidebooks describe it as a "top tourist attraction" for its innumerable monolithic advertising structures, comparable to other more familiar tourist destinations such as the Statue of Liberty, Brooklyn Bridge, Empire State Building, or Grand Central Station. Day and night, Times Square is an illuminated, dynamic display of graphic images sited on every available facade. Two of the most familiar views are the vertical stacks of display screens that demarcate the northeast and southwest edge of the "square."

As part of an attempt to upgrade the area, the number of illuminated signs and their brightness levels have been regulated since 1987 (Boyer 2002). This has played a considerable part in reducing crime incidents and significantly increasing real estate values in the area since the early 1990s. Enhanced by the formation of the Times Square Alliance in 1992 to improve and promote Times Square (also covering 40th Street to 53rd Street between 6th and 8th Avenues, and 46th Street between 8th and 9th Avenue) the place experienced a change in fortunes over the following two decades. Some of this must be attributed to the ever-changing and expanding presence of graphic objects into what has been called "the world's most famous information environment" (Triggs 2009, p. 243).

However, the "bright lights" of corporate advertising that encase Times Square is not the only graphic object on display. The New York Police Department signal their presence at the $43^{\text {rd }}$ Street crossover with distinct neon lettering. This single story station also carries a detailed external mosaic-tiled mural of the city's boroughs, as well as painted lettering reading "Welcome to Times Square ... NYPD”. NYPD uniformed officers are also conspicuous in their distinctive blue uniform, and the Times Square Alliance Public Safety Officers also have their own 
distinct regalia. The U.S. Armed Forces seek to recruit from Times Square with the respective Army, Navy, Air Force and Marines circular crests exhibiting an invisible level of graphic detail in designs closely resembling the Presidential seal. Furthermore, the public may buy a copy of USA Today from a newsstand emblazoned with the newspaper's masthead, or theatre tickets from the booth located with the red TKTS totem protruding above head height.

More mundane are the numerous floor markings and manhole covers that speckle the floorscape (each belonging to different utility suppliers), and subway maintenance access denoted by a fluorescent yellow cover standing out from the grey floor. Furthermore, labelled garbage bins are part of an infrastructure that depends on 50 uniformed Times Square Alliance Sanitation Associates to do their work night and day. Retail premises display familiar and not so familiar fascia lettering and logotypes, whether the relatively sedate Bravo Pizza or the brash McDonald's, whose golden arches appear in multiple at different sizes to be seen from close up and from afar. Some graphic objects, such as a TGI Fridays location sign, are not permanent fixtures and rely on hand-held human support, positioned facing oncoming pedestrians.

All of this can be viewed from the amphitheatre-like steps above the TKTS ticket booth that directly faces the back of the crucifix shaped "Father Duffy" memorial and its inscription-a feature since 1937. This commemorates the work of Lt. Colonel Duffy, pastor of the Holy Cross Church on $42^{\text {nd }}$ Street. Standing at the top of the steps provides a viewing platform for Times Square.

In the same way advertising starts, stops and starts again, the traffic constantly streams through the artery-like streets, characterized by the consistent yellow livery of numerous New York taxis. These physical manifestations represent Times Square as a densely populated array of graphic objects, as seen in Figure 13. As a heterotopia - and "augmented space" (Manovich 2006) - Times Square provides a chaotic context for understanding the products of graphic design and the nature of urban design. In itself it has become a graphic object. 

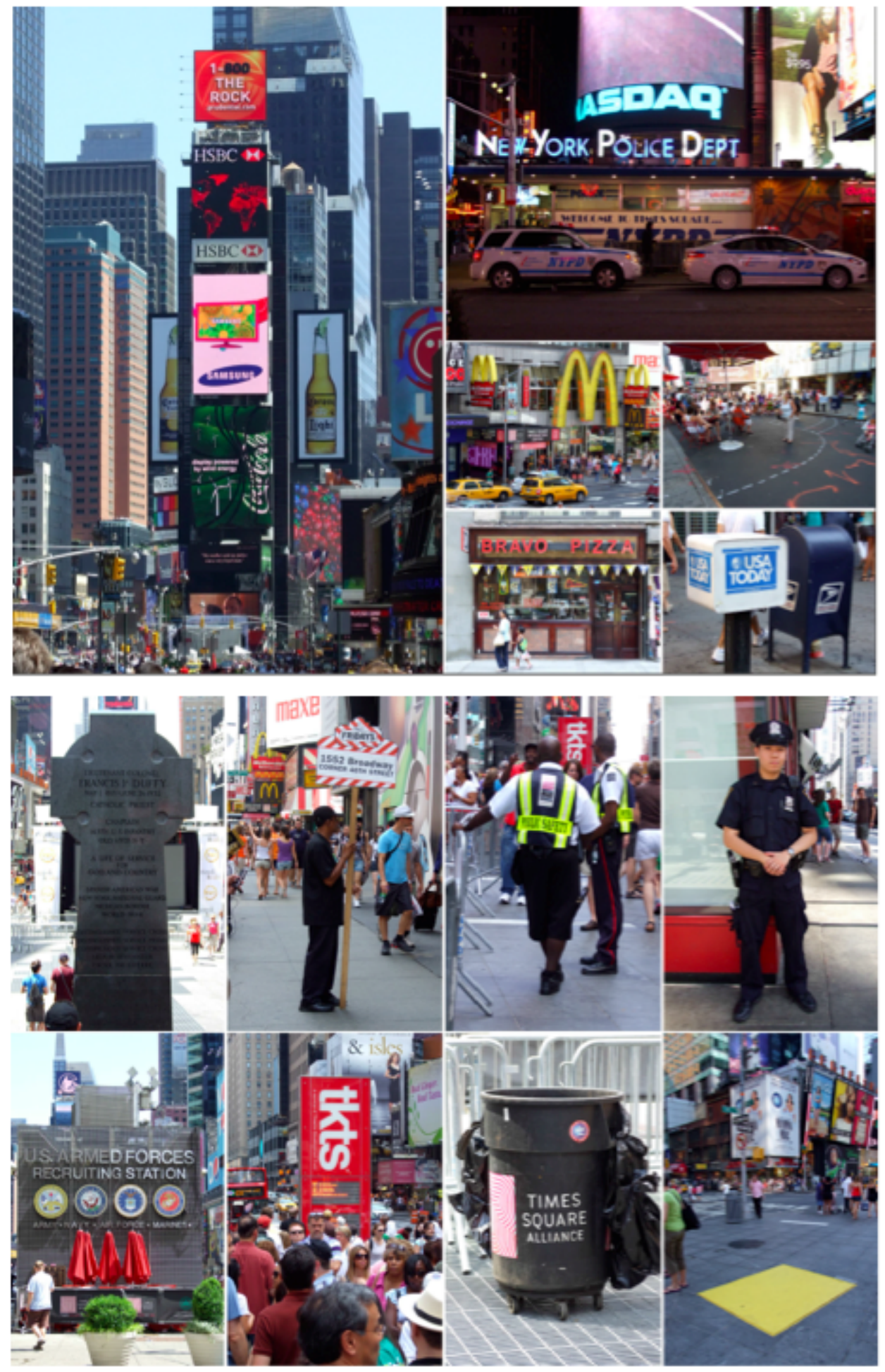

Figure 13. The spectacle of Times Square not only displays a "enclave" of advertising messages, but a myriad of graphic objects functioning in different ways. These serve many actors who integrate with the space for a multitude of reasons to create a heterotopia. This is as mundane as subway maintenance access points through a fluorescent yellow floor cover, as brash as the yellow McDonald's golden arches, or as prevailing as the yellow New York taxi, and the aspiration to the realm of the sacred through a religious memorial to Father Duffy! 
Graphic objects in urban elements: The "Zebra" Crossing

Individual graphic objects each have their history and reason for being. The final example in this article examines the simplest of ubiquitous graphic form: the parallel arrangement of white rectangles that signify a place to cross. This can be found in the busiest of urban places as well as small villages. It is no longer a device used only on roads: its recognition is comparable to objects with more commercial intention such as the McDonald's golden arches symbol.

The zebra crossing (so called by Jim Callaghan, the Member of Parliament and eventual U.K. Prime Minister in the 1970s) is primarily an arrangement of white parallel longitudinal stripes across a carriageway. Usually painted directly on the road surface, it may occasionally be yellow or other colour combinations, depending on the context. These indicate a "safe" place to cross and aspire to give some priority to pedestrians because "Where paths cross roads, the cars have power to frighten and subdue the people walking, even when the people walking have legal right-of-way" (Alexander et al. 1977, p. 281).

The crossing has been used universally since the British Government's Road Research Laboratory (RRL) originated it in the late 1940s. Reports suggest these were installed in 1000 locations in 1949 before nationwide implementation in 1951. Soon after urban roads worldwide adopted and adapted the device and it is now seen in environments such as airports, car parks and inside buildings.

In the UK its appearance is regulated, as stipulated by the diagram in Figure 14, but worldwide the arrangement of parallel lines is often adjusted to suit local conditions. Although the white rectangles have been adopted as a signifier for crossing, they were a later addition and throughout its life additional graphic devices have been added to influence pedestrian behaviour. Initially, in 1934 pedestrian crossings in the UK were indicated by pole-mounted orange spheres and metal studs, but the studs were deemed invisible to motorists. Consequently, the Ministry of Transport experimented with blue-and-yellow and red-and-white combination stripes, eventually deciding on the black-and-white stripes, measuring 40-60cm wide. 


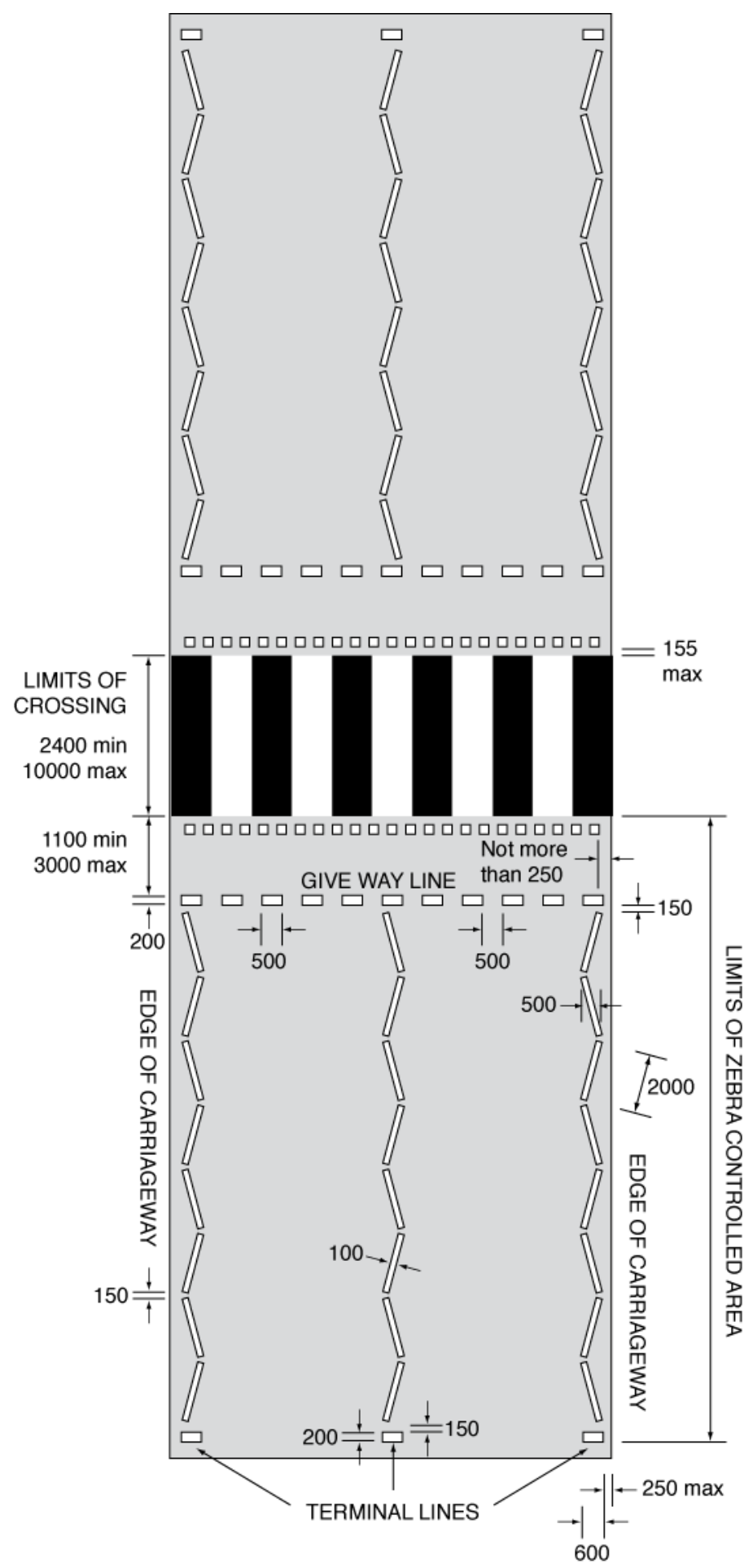

Figure 14. This diagram details the relationship between the defining graphic properties and overall configurational pattern of a Zebra crossing as they should appear on the carriageway in the United Kingdom. It details not only the pedestrian "protected" space, but also the space for vehicles. (Anon 1997, p. 14)

Application in the UK generally conforms closely to the diagram, even though the regulations allow a number of permissible variations (Davies 2005, p. 13). Figure 
15 shows the scope of implementation addressing: how the device copes with the tough demands of a busy intersection, such as New York's Times Square; extension of the rectangles across the length of carriageway; irregular shapes that cover a junction in almost entirety; combination with black when appearing on a muted surface; and in combination with other graphic devices. What is also noticeable is that when not maintained, the painted version can diminish to a "ghost" image, yet when constructed as part of the road surface in contrasting brick or cobble it is durable and sensitive to the local surroundings. Although it works with as few as three stripes, when interspersed with other infrastructure elements such as tramlines, the regularity can be significantly disfigured.

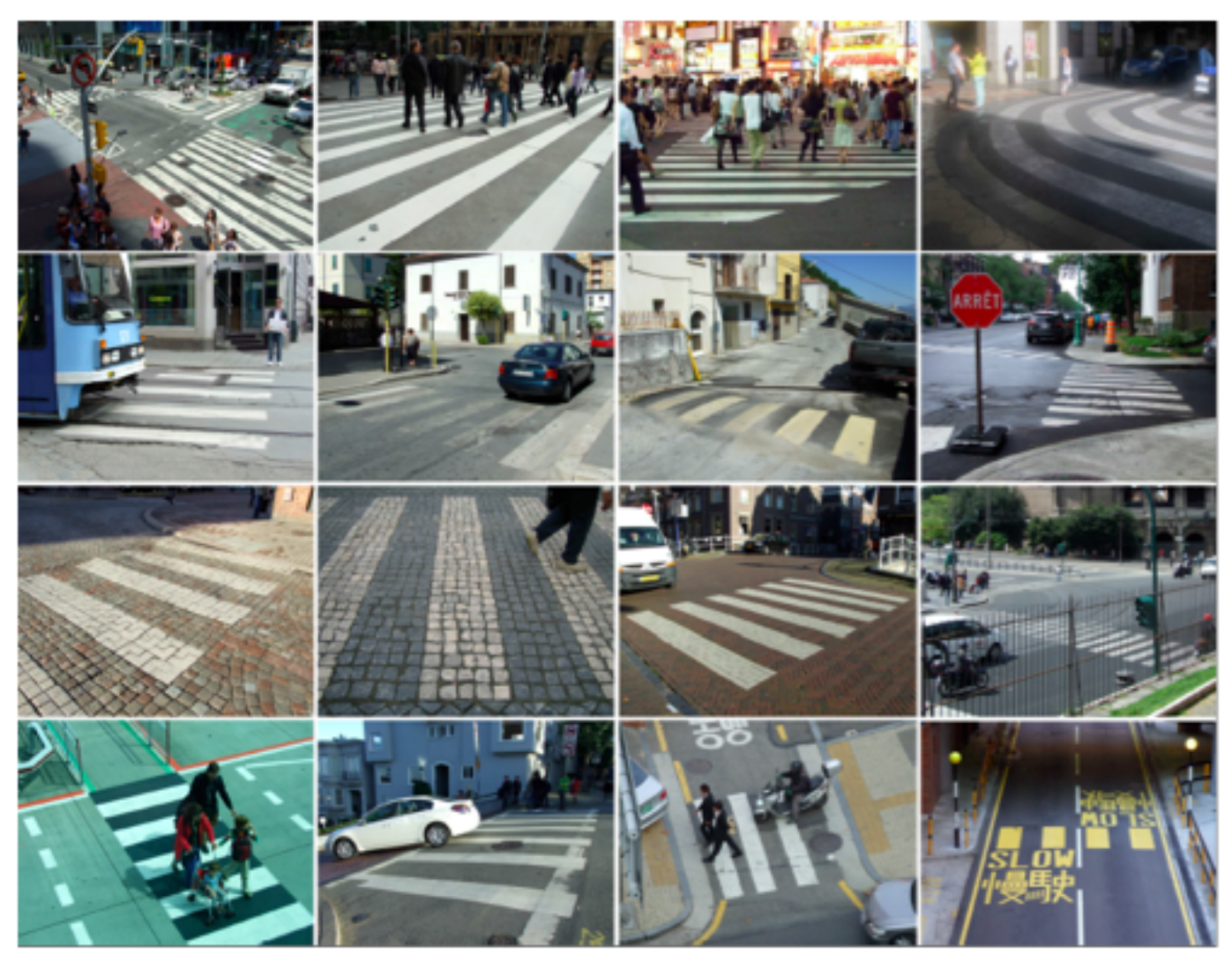

Figure 15. The "Zebra" pedestrian crossing in (left to right, top to bottom): New York, São Paulo, Tokyo, Valencia, Oslo, Isernia, Longano, Montreal, Boras, Lisbon, Delft, Rome, London (Stansted Airport), San Francisco, Seoul, Hong Kong. The basic concept adapts to suit local contexts.

In the UK, opinions about the effectiveness of the Zebra crossing have varied over time. It has been argued that throughout its period of use it has been life-saving and an invaluable contribution to road safety. However, more recently the number of deaths is said to have increased due to the reluctance of drivers to stop in the absence of a red light. Consequently, stripes alone are now considered insufficient and in 2011 news reports began to record its demise. However, its 
function is not only technical. As a landmark, the zebra crossing is a distinct graphic and mental image that will be preserved, despite the risk of extinction in the UK. The Beatles walked on it for their Abbey Road album cover and in 2010 the crossing now in that location was awarded Grade II listed status for its cultural and historical importance and international renown. Furthermore, it's one of Tokyo's top tourist attractions as the Shibuya Crossing, as seen in the before-and-after photographs depicting the spectacle of the spectacle. See Figure 16. It also features as a key location in the motion pictures Babel. Even activists have stencilled poetic quotations on it in Paris (see Burnstone 2005, pp. 2-3, and http://www.thinkdontthink.com/tdtweb.html).
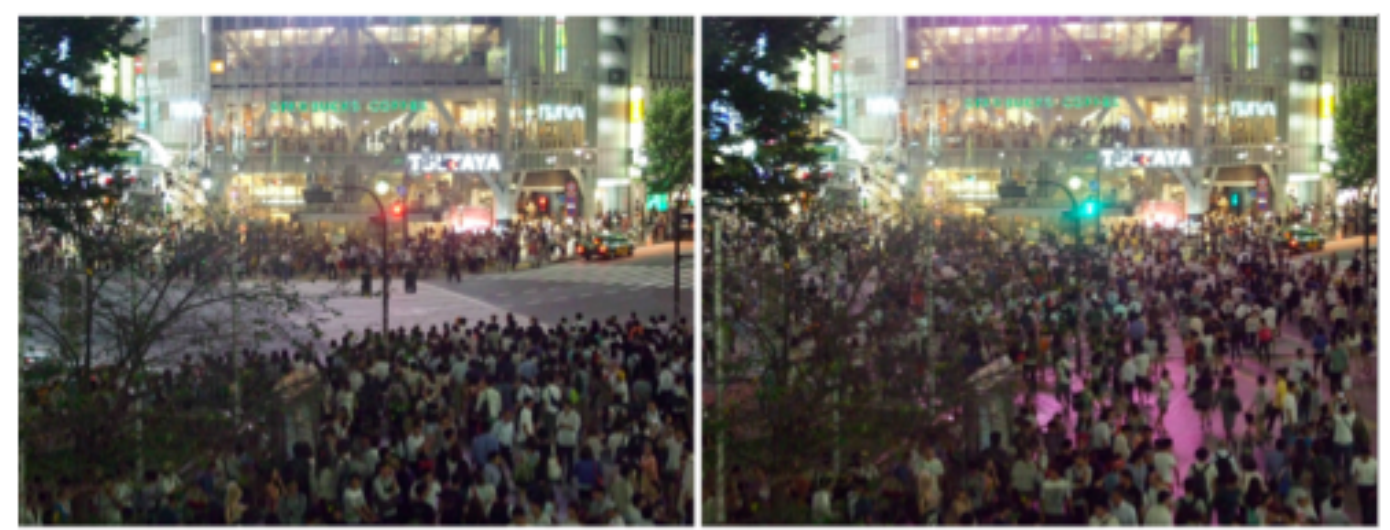

Figure 16. Watching the pedestrians cross the Shibuya crossing at peak time after dark from the second floor window of Starbucks is considered a "top sight" by the Tokyo Lonely Planet guide. These before-and-after photographs illustrate the "scramble."

\section{Implications for urban design}

This article scratches the surface of what is an urban phenomenon in need of more scrutiny than space here allows. In the meantime, some implications for urban design can be drawn from this discussion. To date urban design discourse does not use a cohesive language to encourage understanding of urban graphic objects. Where discussion does happen, it is too often restricted by disciplinary limitations favouring conventional examples such as regulatory signs or markings on a road, but ignores other similar examples that mark a sports pitch in a park. And familiar words cannot be relied on to adequately link academic and professional concerns, as has been noted with the dual use of the word sign. This is confusing.

However, some ideas point the way to understanding the importance of the phenomenon, and the dual interpretation of sign ironically enables this, but when 
spelled out as sign or SIGN. The way Alexander et al. (1977) depict ornamentation offers potential for developing theoretical perspectives across the number of different functions urban graphic objects perform. Both of these interpretations help to span scalar concerns between micrographic and macrographic impact. For instance, in keeping with Alexander et al. (1977) intention to understand how the tiniest of particles or largest of forms mediates between two entities, the detail of the dot over the miniscule letter i in Johnston's typeface for London Underground is a small object in what Walker (1995, p. 87) calls the "macrocosmic system" of the railway network. This points towards potential future research into what happens in-between, say, at the mesographic level. Figure 17 depicts how further research might be framed.

Graphic objects comprise of what cognitive scientists refer to as "defining properties" and "configurational patterns" (Pylyshyn 2007). For example, in the case of a zebra crossing, a white rectangle has no significance until arranged as a multiple and meaning is assigned to it. At the mesographic level - where a number of factors synthesize and transference happens between the graphic image and mental image - the urban graphic object appears to function as what Alexander et al. refer to as a pattern (1977). There are clearly other patterns, suggesting opportunity exists to develop a graphic pattern language for the urban environment.

This article set out to establish the nature of graphic objects as urban objects, manifest through graphic design as urban design. Initially, graphic design was linked to urban design in the same way other built environment professionals are related to urban design, with independent and overlapping concerns. For the relationship between graphic design and urban design to develop further, the properties of graphic design must be better understood within the urban design context, perhaps as a layer of urban design or as part of what Carmona et al. define as the visual dimension of urban design (2010, pp. 169-200), This is concerned with the urban environments "spatial (volumetric) and visual qualities, the artefacts in those spaces and the relationship between them all." A typology of urban graphic objects and an appreciation of graphic designerly ways of knowing will extend the visual dimension of urban design beyond what Carmona et al. discuss as façade design, floorscape, street furniture and landscaping, amongst other concerns. This interpretation of street furniture - including public art and 
signage - comes closest to accommodating the broader issues outlined in this article, but is inadequate despite aspirations towards an holistic understanding. "We always experience the 'whole' rather than any single part in isolation ... all interventions into urban settings are inexorably contributions to an ensemble" (Carmona et al. 2010, p. 170). If this is the case, greater awareness of the role of primary and secondary urban graphic objects will enhance the training of urban designers and associated built environment professionals with an interest in the visual dimension of urban design. This may be achieved through a shared appreciation of design, and presents challenges to the way design is taught and practiced on programmes with an urban or graphic prefix. To enhance crossdisciplinary understanding of graphic design as urban design, three initial priorities come to mind:

- Encourage shared discourse between graphic design and urban design.

- Elaborate on the visual dimension of urban design to include more diversity.

- Extend Alexander's pattern language beyond the function of ornamentation.

The recognition that graphic objects are increasingly valued and acknowledged as defining aspects of urban visual culture provides new potential for urban design. Times Square and the zebra crossing have both been featured here for their graphic distinctiveness. Increasingly graphic designers are involved in designing objects that define spaces - graphic spaces - conflating the metaphor of the printed page used by Lynch (1960) and Moles (1989). The Comedy Carpet work of art in Blackpool is a good example of this. Created by artist Gordon Young in conjunction with graphic designers Why Not Associates, it is part of the multimillion pound regeneration of the Blackpool seafront containing over 160,000 granite letters embedded into concrete, sited in front of Blackpool Tower (Young 2011). In this sense, graphic designed artefacts aspire to the same status as a distinctive building, having implications for the future attractiveness and marketing of places.

\section{Conclusion}

Graphic objects adorn either horizontal surfaces (for example, floorscape), vertical surfaces (for example, walls) or are freestanding (for example, on poles). Occasionally they may also fly through the sky behind a plane! They comprise of structures and infrastructures, in private, public, official and unofficial guise, 
sometimes directly accompanying human performance, rather than merely influencing it. Looking at the urban environment through the lens of graphic design is about understanding the visual communication scene more than sheen: more about representational spaces (Lefebvre 1991) than polished places. It includes the study, interpretation, and construction of graphic modes and communication codes that help form mental images of legible places and spaces. As part of a design process, this requires ability to conceive, plan and make graphic objects that have visual communication as the primary concern, or as a supplement to the way other objects function. The difference is obvious when comparing a flag to a manhole cover: the former exists solely to say something but the latter must first stop you falling down a hole.

Certain places present a plethora of graphic objects that situate us locally, nationally and internationally in the urban. The overabundance in Times Square does this. Conversely, certain objects situate us in no other place, such as the METROPOLITAIN sign at the entrance to the Paris metro, or Johnston's typeface design for London Underground. The same can be said of other graphic devices such as the arrangement of lines that make a sports pitch or running track, unifying the performer with audience at a sporting occasion. On occasion, these lines also determine the shape and scale of architect designed stadia, for example, the "Bird's nest" in Beijing, or simply where a parent should stand to watch their child play football in the park on Sunday morning.

Within cities, the buildings, malls, squares, streets, and parks that evolve from written policies and master plans are the independent products of the built environment professions, principally responsible for assembling cities (Lang 2005). These established design fields are said to overlap with urban design rather than constitute it, acknowledging urban design as having independent concerns as well as collaborative intentions. "Real" urban design integrates these and other public and private sector occupations as diverse as civil servants, arts event organisers and tour operators, to directly and indirectly shape the city (Cowan 1997, p. 16). This article has explored how graphic design also plays its part in the integrative activity of urban design by constituting what urban graphic objects. These objects contribute to the mental image of the city. In specific cases, such as the London Underground diagram, "its representation of London has become one of the most widely accepted mental images of the city" (Forty 2005, 
p. 237). If there is any truth in this, urban graphic objects deserve recognition within the visual dimension of urban design and as a layer of urban design thinking.

\section{Acknowledgements}

The author acknowledges the constructive comments from the journal's reviewers, specifically regarding the structuring of the article and recommendations for more emphasis on key points pertinent to urban design.

\section{References}

Alexander, C. (1964). Notes on the synthesis of form, Cambridge, Massachsettes, and London, England: Harvard University Press.

Alexander, C., Ishikawa, S., Silverstein, M., Jacobson, M., Fiksdahl-King, I., and Angel, S. (1977). A pattern language: towns, buildings, construction, New York: Oxford University Press.

Anon. (1979). Streets Ahead, London: Design Council in association with the Royal Town Planning Institute.

Anon. (1980). The Design of Urban Space, London: The Architectural Press.

Anon. (1997). The Zebra, Pelican and Puffin Pedestrian Crossings Regulations and General Directions 1997, London: The Stationery Office Limited.

Arnold, M. (2013). "Mind the Gap: Translation in a fractured African Society." Third Text, 27(3), 419-435.

Barnard, M. (2005). Graphic Design as Communication, London: Routledge.

Barthes, R. ([1957] 2009). Mythologies, A. Lavers, translator, London: Vintage.

Boardman, D. (1983). Graphicacy and geography teaching, Beckenham: Croom Helm Ltd.

Boyer, M. C. (2002). "Twice-Told Stories: The Double Erasure of Times Square", in I. Borden, J. Kerr, J. Rendell, and A. Pivaro, (eds.), The Unknown City: Contesting Architecture and Social Space. Cambridge: The MIT Press, pp. 30-53.

Buchanan, R. (1989). "Declaration by Design: Rhetoric, Argument, and Demonstration in Design Practice", in V. Margolin, (ed.), Design Issues. Chicago: The University of Chicago Press, pp. 4-22.

Burnstone, D. (2005). "On the Road"Eye. City: Croydon: Quantum Business Media.

Carmona, M., Heath, T., Oc, T., and Tiesdell, S. (2010). Public places - urban spaces: the dimensions of urban design, Oxford: Architectural Press.

Carr, S. (1973). City Signs and Lights: A Policy Study, Massachusetts: The MIT Press.

Carter, S., Dodsworth, F., Ruppert, E., and Watson, S. (2011). "Thinking Cities Through Objects". City: The Open University: Centre for Reseach on Socio-Cultural Change (CRESC).

Clause, R. J., and Claus, K. E. (1971). Visual environment: sight, sign and by-law, Ontario: Collier Macmillan Canada, Ltd. 
Clifford, N. J., Holloway, S. L., Rice, S. P., and Valentine, G. (2009). "Key Methods in Geogaphy". City: SAGE Publications Ltd: London, pp. 555.

Cowan, R. (1997). "The Connected City: A New Approach to Making Cities Work". City: Urban Initiatives: London.

Crosby, T. (1973). The environment game: Penguin Books.

Cross, N. (2006). Designerly ways of knowing, London: Springer-Verlag.

Cullen, G. (1971). The Concise Townscape, London: The Architectural Press.

Davies, C. (2005). "Design Notes"Surveyor. City: Hemming Information Services: London.

Dwiggins, D. A. ([1922] 1999). "New kind of printing calls for new design", in M. Bierut, J. Helfland, S. Heller, and R. Poyner, (eds.), Looking Closer 3. New York: Allworth Press, pp. 14-18.

Forty, A. (2005). Objects of Desire: Design and Society since 1750, London: Thames and Hudson.

Friedman, K. (1998). "Building Cyberspace. Information, Place and Policy." Built Environment, $24(2 / 3), 83-103$.

Gouveia, A. P. S., Farias, P. L., and Gatto, P. S. (2009). "Letters and Cities: Reading the Urban Environment with the Help of Perception Theories." Visual Communication, 8(3), 339-348.

Helfland, J. (2001). Screen: essays on Graphic Design, New Media, and Visual Culture, New York: Princeton Architectural Press.

Jubert, R. ([2005] 2006). Tyopgraphy and Graphic Design: from Antiquity to the Present, D. Radzinowicz and D. Dusinberre, translator, Paris: Flammarion.

Knobel, L. (1985). The Faber guide to twentieth-century architecture: Britain and Northern Europe London: Faber and Faber.

Lang, J. (1994). Urban Design: the American experience, New York: John Wiley \& Sons, Inc.

Lang, J. (2005). Urban design: a typology of procedures and products, Oxford: Architectural Press.

Lefebvre, H. (1991). The production of space / Henri Lefebvre; translated by Donald Nicholson Smith, Oxford: Blackwell Publishing.

Leite, C. (2013). "Sustaibable Megacity Visions from São Paulo", in B. McGrath, (ed.), Urban design ecologies. Chichester: John Wiley \& Sons Ltd, pp. 197-211.

Livingston, A., and Livingston, I. (1992). The Thames and Hudson Dictionary of Graphic Design and Designers, London: Thames and Hudson Ltd.

Lucas, G. (2013). "A most distinctive corporate typeface"Creative review. City: Centaur Media: London, pp. 26-30.

Lynch, K. (1960). The image of the city, Cambridge, Massachusetts, and London: The MIT Press.

Manghani, S., Arthur, P., and Simons, J. (2006). "Images: a Reader". City: SAGE Publications Ltd: London.

Manovich, L. (2006). "The Poetics of Augmented Space." Visual Communication, 5(2), 219-240.

McLean, R. (2000). How Typography Happens, London, UK and New Castle, USA: The British Library and the Old Knoll Press.

Meggs, P., and Purvis, A. W. (2006). Meggs' history of graphic design, Hoboken: John Wiley \& Sons, Inc. 
Mitchell, W., J. (2005). Placing words : symbols, space, and the city, Cambridge: The MIT Press.

Mitchell, W. J. T. (1986). Iconology: image, text, ideology, Chicago: The University of Chicago Press.

Moles, A. M. (1989). "The legibility of the world: a project of graphic design", in V. Margolin, (ed.), Design discourse : history, theory, criticism. Chicago: The University of Chicago Press, pp. 119129.

Mollerup, P. (2005). Wayshowing, Baden: Lars Müller Publishers.

Monmonier, M. (1993). "Mapping it out: Expository Cartography for the Humanities and Social Sciences", Mapping it out: Expository Cartography for the Humanities and Social Sciences. Chicago: University of Chicago Press, pp. 4-12.

Ovenden, M. (2013). London Underground by Design, London: Penguin Books Ltd.

Pylyshyn, Z. W. (2007). Things and places : how the mind connects with the world, Cambridge and London: The MIT Press.

Robinson, A. (2007). The Story of Writing, London: Thames and Hudson Ltd.

Rowe, C., and Koetter, F. (1978). Collage city, Cambridge, Masachusetts, and London, England: The MIT Press.

Shane, D. G. (2011). Urban Design Since 1945-A Global Perspective, Chichester: John Wiley and Sons Limited.

Strauss, A. L. (1961). Images of the American City, New York: The Free Press of Glencoe.

Terragani, E. (2012). "The Phaidon Archive of Graphic Design", A. Fitzpatrick, A. Roff, and D. Thakara, (eds.). City: Phaidon Press Limited: London.

Triggs, T. (2009). "Editorial." Visual Communication, 8(3), 243-247.

van der Waarde, K. (2009). On graphic design: listening to the reader: Avans Hogeschool Research Group Visual Rhetoric AKV | St. Joost.

Venturi, R., Scott Brown, D., and Izenour, S. (1977). Learning from Las Vegas, Cambridge, Massachusettes, and London: The MIT Press.

Walker, J. A. (1995). "The London Underground diagram", in T. Triggs, (ed.), Communicating Design: Essays in Visual Communication. London: B.T. Batsford Ltd.

Ward, J. (2001). Weimar surfaces: urban visual culture in 1920s Germany, Berkeley, Los Angeles and London: University of California Press.

Williams, R. (1983). Keywords: a vocabulary of culture and society, London: Fontana Press.

Young, G. (2011). "The Comedy Carpet". City: Gordon Young Ltd: http://comedycarpet.co.uk.

Zeisel, J. (2006). Inquiry by Design, New York: W.W. Norton \& Company Inc. 